\title{
The Effects on Inclined Application of Shear Stud Connectors in Negative Bending Region of the Composite Beam
}

\author{
Bavan, M.* \\ Student, Department of Civil Engineering, University Teknologi Malaysia, Malaysia
}

Baharom, S. B.

Senior Lecturer, Department of Civil and Structural Engineering, National University of

Malaysia, Malaysia

Osman, S. A.

Assoc. Prof. Department of Civil and Structural Engineering, National University of

Malaysia, Malaysia

\begin{abstract}
This paper is concerned with finite element study on the ultimate load behaviour of steel-concrete composite beams in terms of inclined application of shear stud connectors in the negative bending region. A full-scale finite element (FE) model for a composite beam was developed and validated with experimental analysis from existing literature. The validated FE model was taken for parametric study of this research by applying the shear stud connectors in inclined position. Then the developed FE model was tested to failure and the failure modes were monitored throughout the analysis such that strain in both concrete and steel, and of displacements were studied to obtain a complete picture of elastic and ultimate load behaviour. In comparison of the installation of shear stud connectors in inclined position with vertical position, the FE model results indicate that the load-carrying capacity developed with postponing the failure criteria occurred in the components of the composite beam.
\end{abstract}

Keywords: Steel-Concrete Composite Beam, Inclined Shear Studs, Negative Bending Region, Load-Carrying Capacity, Failure Modes 